\title{
New Modified Equation of Contact Lens Method in Determining Post Myopic Laser Refractive Surgery Corneal Power
}

\author{
Md Muziman Syah $M M^{\mathrm{a}, \mathrm{b}}$, Mutalib $\mathrm{HA}^{\mathrm{a}}$, Sharanjeet Kaur $M \mathrm{~S}^{\mathrm{a}}$, Khairidzan $M K^{\mathrm{c}}$ \\ ${ }^{a}$ Programme of Optometry and Visual Science, Faculty of Health Sciences, Universiti Kebangsaan Malaysia. \\ ${ }^{b}$ Department of Optometry and Visual Science, Kulliyyah of Allied Health Sciences, International Islamic University Malaysia \\ 'Department of Ophthalmology, Kulliyyah of Medicine, International Islamic University Malaysia.
}

\begin{abstract}
Introduction: The purpose of this study was to derive a modified equation for contact lens method (CLM) in calculating post myopic laser refractive surgery corneal power. Methods: A total of 93 subjects who underwent myopic laser refractive surgery at IIUM Eye Specialist Clinic were recruited. The accuracy of postoperative corneal power using the standard CLM and newly-derived contact lens modified method $\left(C L M_{\bmod }\right)$ were compared to the standard comparison method ; the historical method $(\mathrm{HM})$. The $C L M_{\bmod }$ equation was derived by adjusting postoperative corneal power of CLM according to amount of refractive change. Results: The mean postoperative corneal power using standard CLM was significantly higher than HM (mean difference: $-0.24 D, p<0.001)$. Fifty seven percent $(n=53$ eyes) of the standard CLM results were within $\pm 0.50 \mathrm{D}$ of $\mathrm{HM}$ results. The difference between postoperative corneal power using standard CLM and $\mathrm{HM}$ increased significantly with the amount of refractive change $(r=0.835 ; p<0.001)$. The mean postoperative corneal power of CLM mod showed that there was no statistical significant difference compared to the HM results (mean difference: $0.00 \mathrm{D}, \mathrm{p}=0.964$ ). Eighty eight percent ( $n=82$ eyes) of the CLM mod results were within $\pm 0.50 \mathrm{D}$ of $\mathrm{HM}$ results with improvement of $31 \%$ from the standard CLM results. Conclusion: The CLM mod equation provides more accurate calculation in determining post myopic laser refractive surgery corneal power. In near future, this modified equation can be used as an alternative equation to calculate postoperative corneal power when the preoperative data is unavailable.
\end{abstract}

KEYWORDS: Equation, contact lens method, contact lens modified method, myopic laser refractive surgery, biometry post LASIK

\section{INTRODUCTION}

Total corneal power is determined by the anterior and posterior refractive surface of the cornea. The accuracy of the corneal power measurement is a major concern especially in post laser refractive surgery eyes. ${ }^{1-2}$ Corneal power routinely obtained from conventional keratometer and Placido-disc corneal topographer based on simulated keratometry $(\mathrm{sim}-\mathrm{K})$ value. These instruments measure only $3.0 \mathrm{~mm}$ paracentral cornea on the anterior refractive surface. Therefore, two assumptions are applied to extrapolate corneal

Corresponding author:

Md Muziman Syah Md Mustafa, PhD

Programme of Optometry and Visual Science,

School of Healthcare Sciences,

Faculty of Health Sciences,

Universiti Kebangsaan Malaysia,

Jalan Raja Muda Abdul Aziz,

50300 Kuala Lumpur, Malaysia.

Tel: 603-92897495

Fax: 603-2691 0488

Email: phd.optom@gmail.com power measurement. The assumptions are the surface of cornea has a uniform curvature and the posterior/anterior corneal curvature ratio has a fixed value of $0.883(6.8 / 7.7 \mathrm{~mm})$ based on Gullstrand's model eye. From the assumptions, these instruments use a keratometric index 1.3375 in converting the measured anterior corneal curvature to the corneal power, instead of the higher actual corneal refractive index of 1.376. These assumptions are no longer valid in post laser refractive surgery eyes because the central region of the anterior corneal surface has been changed by the excimer laser while retaining the shape of the posterior surface. Thus, the curvature of the anterior cornea surface becomes non-uniform and the posterior/anterior corneal curvature ratio is changed in post laser refractive surgery eyes. Because of these changes, the conventional keratometer and topographer can be inaccurate in measuring postoperative corneal power, this can result in miscalculation of intraocular lens (IOL) power and unintentional postoperative ametropia after the cataract surgery. ${ }^{1,3}$

The IOL power calculation errors in post laser refractive surgery eyes mostly arise from the 
incorrect measurement of the corneal power and the erroneous prediction of the effective lens position (ELP) by third or fourth generation IOL power formulas. ${ }^{1,4-5}$ However, most of previous literatures reported that the inaccurate estimation of the corneal power after laser refractive surgery is the main factor of IOL power miscalculations. ${ }^{6-7}$ As for the accuracy in the ELP estimation, it can be improvised by applying double-K method ${ }^{4}$.

Since the postoperative corneal power is a very important data for IOL power calculation, an alternative method is required when the preoperative data are unavailable. Although many methods were proposed in previous years back until now, hardly any single method be able to provide an ultimate accurate postoperative corneal power value. ${ }^{1}$ Most of the latest proposed methods require sophisticated instrument such as optical coherent tomographer ${ }^{3}$, Pentacam HR $^{8}$, IOLMaster ${ }^{9}$, Orbscan $^{10}$ and rely on the Holladay 2 consultant software ${ }^{7}$, which are relatively expensive and thus may not available in certain clinical setting. Furthermore, certain method such as Jin-modified Maloney Method is designed for only the Chinese eyes. ${ }^{7}$ Contact lens method (CLM) is a relatively inexpensive and readily available in most of optometry and ophthalmology setting. However, this method has not received much attention lately and is rarely found in published peer reviewed journal after year 2005.

The CLM is based on determination of the difference between the manifest refraction with a rigid gas permeable (RGP) lens of a known base curve (BC) and without it. The anterior corneal power can be estimated from the $B C$ of the RGP lens with the assumption that the power of the RGP lens is plano. Theoretically, if the corneal curvature measured is of the same curvature with the RGP lens, and a plano RGP lens is used, the overrefraction results would be the same as subject's refractive error. The idea is to use RGP lens to correct the irregularities of the cornea shape post laser refractive surgery and simulate the postoperative corneal surface to mimic normal cornea. Several authors have reported that the accuracy of CLM was highly variable in determining the corneal power after laser refractive surgery. ${ }^{11-15}$ However, to the best of our knowledge, no studies had proposed an improved equation for the CLM in obtaining an accurate postoperative corneal power. This area is still unexplored which demands an improvement in the RGP lens fitting strategies and the development of equation of the CLM.

The aims of this study were to evaluate the accuracy of the standard CLM and subsequently to modify the CLM equation in calculating corneal power after myopic laser refractive surgery. It is intended that this present work will yield an accurate postoperative corneal power determination for IOL power calculation using the $\mathrm{CLM}_{\bmod }$ when preoperative information of laser refractive is inaccessible. The HM was set as a standard for comparison.

\section{MATERIALS AND METHODS}

Ninety three subjects who had undergone myopic laser refractive surgery at IIUM Eye Specialist Clinic within January 2013 to June 2014 were recruited. The refractive surgery was performed by a single surgeon (K.M.K.) using Mel 80 excimer laser (Carl Zeiss Meditec AG, Germany) with treatment zone of $6.0 \mathrm{~mm}$. The subjects had the surgery done six month before to ensure postoperative recovery had completed and postoperative refraction of $\leq 1.00 \mathrm{D}$ was achieved. Only subjects with best corrected visual acuity (BCVA) of $\leq 6 / 9$ were enrolled to aviod measurement error as the accuracy of CLM was lower when the subjects' visual acuity reduced. ${ }^{12}$ Those subjects who had corneal astigmatism $>2.00 \mathrm{D}$ were excluded to ensure good centration of RGP lens fitting. All subjects had no corneal abnormalities or other ocular diseases, systemic diseases and other ocular surgery history.

The purposes, benefits, risks and procedures of this study were explained to all subjects. A written consent form in accordance with institutional guidelines and the tenets of the Declaration of Helsinki was signed by each subject. This research was approved by the Ethical Committee, Pusat Perubatan Universiti Kebangsaan Malaysia, UKM (Ref: UKM1.21.3/244/NN-056-2013).

\section{Measurements}

During the data recruitment visit, the subjects who fulfilled the inclusion criteria had undergone several ophthalmic procedures including preliminary slit lamp examination, both objective and subjective refraction, keratometry using IOLMaster (Carl Zeiss Jena $\mathrm{GmbH}$, Germany) and Atlas 9000 topographer (Carl Zeiss Meditec AG, Germany), RGP lens fitting and overrefraction with the RGP lens. Postoperative corneal power was determined using several methods are as follow;

1. Direct keratometry measurement using Atlas 9000 topographer and IOLMaster.

2. Historical method.

It is based on the theory that laser refractive surgery has altered the corneal curvature that induced the manifest refraction change at corneal plane. Thus, the postoperative corneal power is determined by subtracting the preoperative corneal power to the change in manifest refraction. The equation of $\mathrm{HM}$ is as 
follows;

$$
H M=K_{\text {pre }}-\left[R_{\text {post }}-R_{\text {pre }}\right]
$$

$\mathrm{HM}$ = estimated of the true postoperative corneal power of $\mathrm{HM}$.

$\mathrm{K}_{\text {pre }}=$ average preoperative corneal power.

$R_{\text {pre }}=$ preoperative spherical equivalent of refraction at corneal plane $(12 \mathrm{~mm})$.

$\mathrm{R}_{\text {post }}=$ stable postoperative spherical equivalent of refraction at corneal plane $(12 \mathrm{~mm})$.

Most literatures reported that the HM was considered as a standard comparison method in estimating postoperative corneal power. It was frequently used as a standard for comparison in the previous research works. ${ }^{4,6,7,13}$

3. Contact lens method.

This method measures the difference between the sum of the RGP lens BC, power and spherical equivalent (SE) of the overrefraction, with the SE of the manifest refraction without a RGP lens on the subject's eye. All the SEs were converted at corneal plane. The CLM equation is as follows;

$$
C L M=C_{B C}+C_{R x}+R_{C L}-R_{0}
$$

CLM = estimated of the true postoperative corneal power of CLM.

$C_{B C}=$ base curve of the contact lens in diopter.

$C_{R x}=$ spherical power of the contact lens in diopter.

$\mathrm{R}_{\mathrm{CL}}=\mathrm{SE}$ of refraction with the contact lens at corneal plane $(12 \mathrm{~mm})$.

$\mathrm{R}_{0} \quad=\mathrm{SE}$ of refraction without the contact lens at corneal plane $(12 \mathrm{~mm})$.

The CLM was carried out using the Boston Envision ${ }^{\circledR}$ bi-aspheric RGP lens (Oculus) with the $B C$, power and diameter of 7.30 to $8.30 \mathrm{~mm}$ in $0.10 \mathrm{~mm}$ step, $-3.00 \mathrm{D}$ and $9.60 \mathrm{~mm}$ respectively. The RGP lens was initially fitted on steeper keratometry reading obtained from the IOLMaster or Atlas 9000. The lens fitting assessment was performed under slit lamp examination to ensure the lens had the best centration and cover the whole pupil. The BCs of RGP lenses were changed until the best centration successfully achieved. Then, the overrefraction was performed. No dilating agent was instilled in order to measure physiological corneal refractive power. ${ }^{12}$ All measurements were conducted by a single examiner. The obtained parameters were inserted into the CLM equation to calculate the postoperative corneal power.

4. Contact lens regression method $\left(C L M_{\text {reg }}\right)$.

Postoperative corneal power was calculated based on regression analysis between the HM against CLM.

5. Contact lens modified method (CLM $\left.M_{\text {mod }}\right)$.

Postoperative corneal power was calculated based on regression analysis which the CLM was adjusted according to the amount of refractive change induced by laser refractive surgery (SE Change $\left._{\text {post-pre }}\right)$.

\section{Statistical Analysis}

All the data obtained were analyzed using Statistical Package for the Social Sciences (SPSS) software version 20.0, Microsoft Excel software version 7 and MedCalc software version 12.3 for Windows. Data normality were tested using Shapiro-Wilk test, visual inspection of the relevant histogram and skewness result.

Prior to agreement analysis, a two tailed paired sample $t$ test was employed to determine the differences in the mean calculated postoperative corneal power between the two compared methods. The confidence level $(p)$ of less than 0.05 was set to define statistical significance for the comparison.

\section{RESULTS}

The mean age of the subjects $(n=93)$ was $31.95 \pm$ 6.18 years ranging from 20 to 45 years. The subjects consisted of 39 males (41.9\%) and 54 females (58.1\%). Distribution of the subjects based on surgical modality demonstrated that 42 subjects (45.1\%), 41 subjects (44.1\%) and 10 subjects (10.8\%) were from the laser in-situ keratomileusis (LASIK), photorefractive keratectomy (PRK) and epithelial laser in-situ keratomileusis (Epi-LASIK) respectively. The mean preoperative SE, mean postoperative SE and mean SE change after laser refractive surgery as shown in Table I. 
Table I. Distribution of subjects' refractive and keratometric values

\begin{tabular}{llll}
\hline Refractive \& Keratometric Values (D) & Mean & SD & Range \\
\hline $\mathrm{SE}_{\text {pre }}$ (spectacle plane) & -4.09 & 1.88 & -1.25 to -9.25 \\
$\mathrm{SE}_{\text {post }}$ (spectacle plane) & -0.12 & 0.33 & 0.63 to -1.00 \\
SE Change & & 1.68 & 1.23 to 8.85 \\
$\mathrm{~K}_{\text {pre }}$ & 3.74 & 1.14 & 40.48 to 46.19 \\
$\mathrm{~K}_{\text {post }}$ & 43.69 & 1.11 & 38.01 to 43.25 \\
\hline
\end{tabular}

SD -standard deviation; $\mathrm{SE}_{\text {pre }}$-spherical equivalent before laser refractive surgery; $\mathrm{SE}_{\text {post }}$-spherical equivalent after laser refractive surgery; SE Change $_{\text {post-pre }}$-spherical equivalent change (the amount of refractive change induced by laser refractive surgery); $\mathrm{K}_{\text {pre }}$-keratometric value before laser refractive surgery; $K_{\text {post }}$-keratometric value after laser refractive surgery.

The mean postoperative corneal power by the topographer, IOLMaster and CLM were significantly overestimated the $\mathrm{HM}$ result respectively. Whereas, both of the $C L M_{\text {reg }}$ and $C L M_{\bmod }$ results were no differences to the HM results (Table II).

Table II. Differences of postoperative corneal power using various methods to the historical method

\begin{tabular}{|c|c|c|c|}
\hline \multirow[b]{2}{*}{ Method } & \multicolumn{3}{|c|}{ Postoperative Corneal Power (D) } \\
\hline & Mean (SD) & Range & \\
\hline HM & $39.95(1.55)$ & \multicolumn{2}{|c|}{35.49 to 43.45} \\
\hline $\mathrm{K}_{\text {post }}$ (Atlas 9000) & $40.79(1.11)$ & \multicolumn{2}{|c|}{38.01 to 43.25} \\
\hline $\mathrm{K}_{\text {post }}$ (IOLMaster) & $40.43(1.21)$ & \multicolumn{2}{|c|}{37.05 to 43.13} \\
\hline CLM & $40.19(1.22)$ & \multicolumn{2}{|c|}{36.65 to 42.83} \\
\hline CLM reg & $39.97(1.44)$ & \multicolumn{2}{|c|}{35.79 to 43.08} \\
\hline CLM mod & $39.95(1.56)$ & \multicolumn{2}{|c|}{35.54 to 43.27} \\
\hline Difference Between Methods & Mean Difference (SD) & $t$-Stat. & $p$-Value \\
\hline $\mathrm{HM}-\mathrm{K}_{\text {post }}($ Atlas 9000$)$ & $-0.84(0.80)$ & -10.19 & $<0.001$ \\
\hline $\mathrm{HM}-\mathrm{K}_{\text {post }}$ (IOLMaster) & $-0.48(0.68)$ & -6.78 & $<0.001$ \\
\hline $\mathrm{HM}-\mathrm{CLM}$ & $-0.24(0.62)$ & -3.76 & $<0.001$ \\
\hline $\mathrm{HM}-\mathrm{CLM}_{\text {reg }}$ & $-0.02(0.59)$ & -0.26 & 0.799 \\
\hline$H M-C L M_{\bmod }$ & $0.00(0.34)$ & 0.05 & 0.964 \\
\hline
\end{tabular}

The correlation between the $\mathrm{HM}$ and CLM was excellent with $r$-value of 0.926 and $p<0.001$, but the range of $95 \%$ limit of agreement (LOA) was fairly wide (Figure 1 and Table III). The regression equation between the HM and CLM is as follows;

$$
\mathrm{CLM}_{\text {reg }}=1.179[\mathrm{CLM}]-7.423
$$




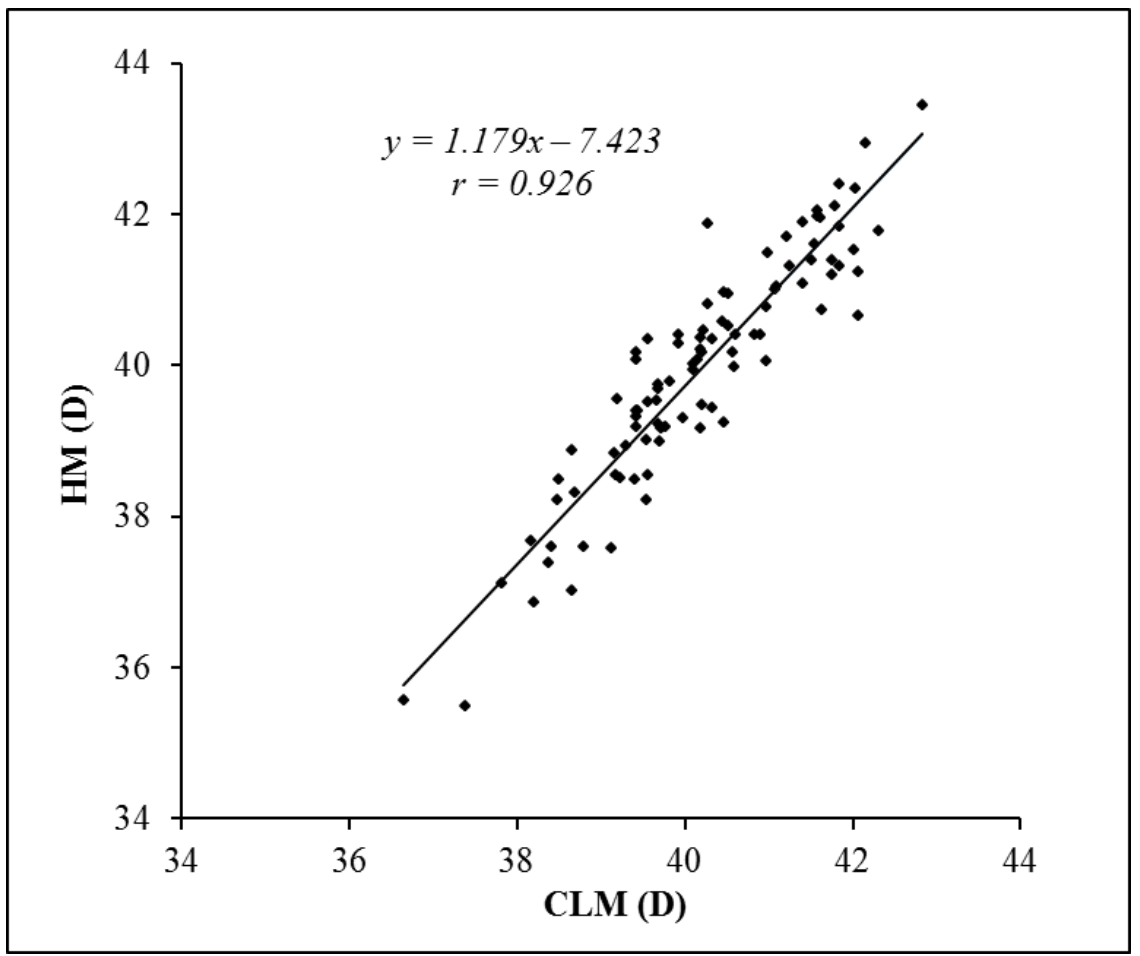

Figure 1. Correlation of calculated postoperative corneal power using historical method versus contact lens method

Fifty-seven percent (57\%) of CLM results were within $\pm 0.50 \mathrm{D}$ of $\mathrm{HM}$ results. When the postoperative corneal power was determined using the $C L M_{\text {reg }}, 63 \%$ of $C L M_{\text {reg }}$ results were within \pm 0.50 $D$ of $H M$ results. The difference between the HM and CLM was $70 \%$ explained by operative refractive change. Thus, we modified the obtained regression equation $(y=-0.312 x+0.922)$ with the operative refractive change as a significant predictor for the difference of HM and CLM (Figure 2). The newlyderived CLM mod equation is as follows;

$C L M_{\text {mod }}=C L M-0.312\left[S E\right.$ Change $\left._{\text {post-pre }}\right]+0.922$

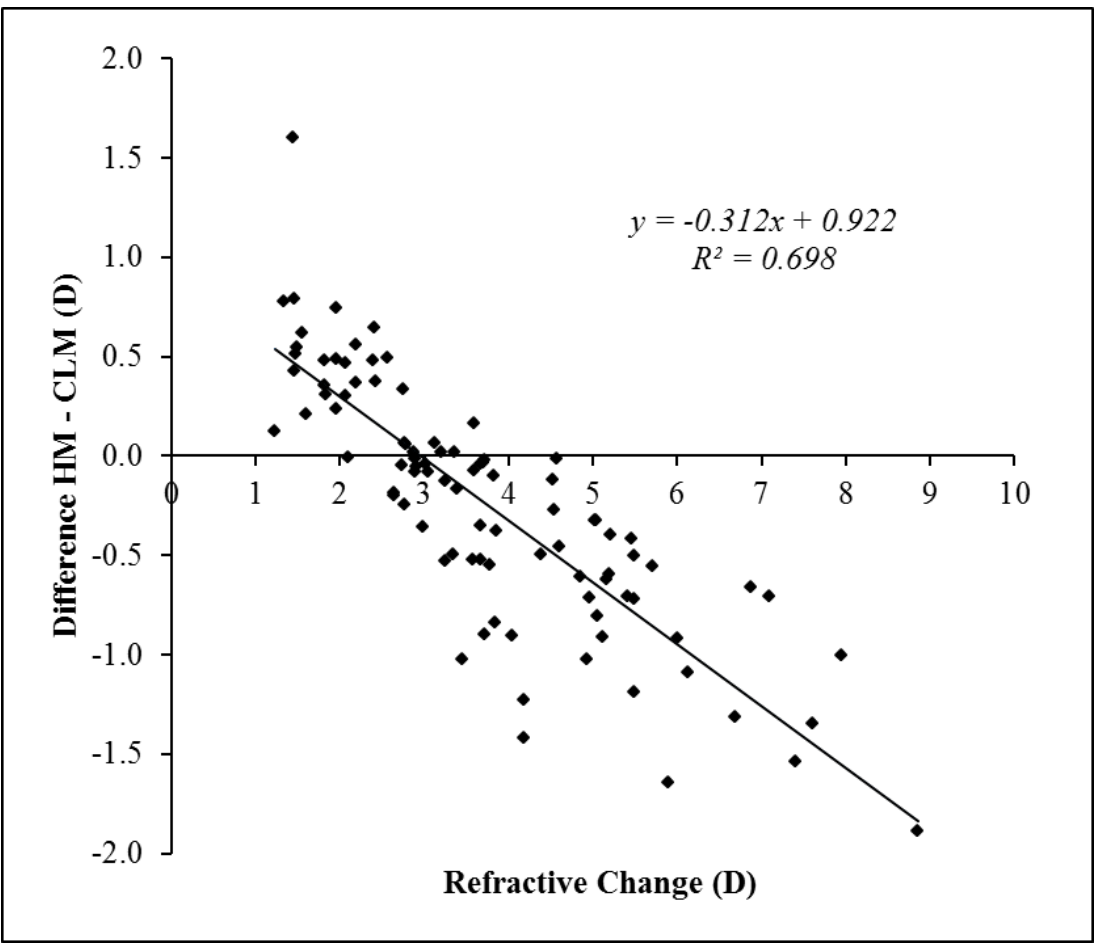

Figure 2. Difference between calculated postoperative coneal power using historical method and contact lens method versus operative refractive change 
By applying this modified equation, $88 \%$ of $C L M_{\bmod }$ results were within $\pm 0.50 \mathrm{D}$ of $\mathrm{HM}$ results. The correlation between the methods was extremely excellent with the range of $95 \%$ LOA became closer and tighter (Table III).

Table III. Comparison between calculated postoperative corneal power using historical method and various contact lens methods

\begin{tabular}{lllllll}
\hline Method & Pearson's r & $\begin{array}{l}\text { Lower 95\% } \\
\text { LOA (D) }\end{array}$ & $\begin{array}{l}\text { Upper 95\% } \\
\text { LOA (D) }\end{array}$ & $\begin{array}{l}\text { Within } \\
\pm 0.50 \mathrm{D}(\%)\end{array}$ & $\begin{array}{l}\text { Within } \\
\pm 0.75 \mathrm{D}(\%)\end{array}$ & $\begin{array}{l}\text { Within } \\
\pm 1.00 \mathrm{D}(\%)\end{array}$ \\
\hline $\mathrm{CLM}$ & 0.926 & -1.47 & 0.98 & 57.0 & 77.4 & 87.1 \\
$\mathrm{CLM}_{\text {reg }}$ & 0.926 & -1.16 & 1.13 & 63.4 & 82.8 & 90.3 \\
$\mathrm{CLM}_{\text {mod }}$ & 0.976 & -0.67 & 0.67 & 88.2 & 95.7 & 97.8 \\
\hline
\end{tabular}

\section{DISCUSSION}

As laser refractive surgery has gained popularity since its first introduction, patients who had undergone the procedure earlier might be developed cataract which require IOL implantation to restore their vision. A reliable method in estimating postoperative corneal power which does not require preoperative data must be made available. CLM is an alternative strategy in dealing with this situation and relatively inexpensive to be performed since the contact lens trial set for assessment is commonly available.

From our results, the accuracy of the CLM was considered as moderate. However, our CLM result provides lower mean difference (MD) and SD of difference than those reported by previous works, ${ }^{11,13-16}$ even though we conducted on larger sample size. We assume that these better findings may be attributed to several factors; 1 ) wider range of the RGP lens BC was used than only one BC used in Kim et al., ${ }^{13} 2$ ) assessment was focused on good centration fitting rather than on steep $^{11}$ or alignment fitting strategies, ${ }^{15} 3$ ) overrefraction was performed in dry condition which evaluated the physiological corneal power, and 4) subjects with good BCVA were recruited as compared to Taheri et al. ${ }^{14}$ and Qazi et al. studies, ${ }^{16}$ where their subjects already had developed cataract.

As the accuracy of calculated postoperative corneal power by standard CLM equation is only at moderate level, regression analysis was employed to determine the main predictor that would improve the CLM equation. Based on our findings,

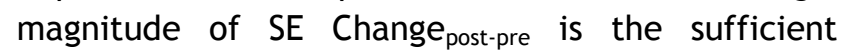
predictor to significantly improve the postoperative corneal power outcome. The regression equation derived by SE Change post-pre $_{\text {as }}$ the predictor, drastically enhanced the CLM accuracy by modifying $0.31 \mathrm{D}$ for every diopter of operative correction (CLM $M_{\text {mod }}$ equation). By using this modified equation, the accuracy of $C L M_{\text {mod }}$ results were within $\pm 0.50 \mathrm{D}$ of $\mathrm{HM}$ results increased about $31 \%$ from the standard $C L M$ result with a lower SD of the difference. If the

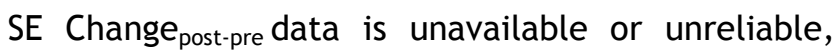
the regression equation solely derived based on CLM can be considered (CLM reg equation). After applying this regression equation, $63 \%$ of $C L M_{\text {reg }}$ values were within $\pm 0.50 \mathrm{D}$ of $\mathrm{HM}$ values.

To the best of our knowledge, this study is the first work on CLM which proposes the newly improved $C L M_{\text {mod }}$ equation by adjusting the CLM overestimation based on magnitude of SE Change postpre. For CLM study comparison, a large diameter $(15.0 \mathrm{~mm})$ RGP lens findings in Joslin et al. ${ }^{11}$ was comparable with our CLM mod which utilized a smaller diameter $(9.60 \mathrm{~mm})$. This present $C L M_{\text {mod }}$ provides even higher percentage of eyes $(88 \%)$ were within $\pm 0.50 \mathrm{D}$ of $\mathrm{HM}$ values as compared to the Joslin et al.'s finding (79\%). The drawback of a larger diameter RGP lens is that the trial lens set is not usually readily available in our local general optometry or ophthalmology setting. This current work suggests that the use of a smaller diameter RGP lens fitted using good lens centration strategy and this modified CLM mod equation must be employed for an accurate postoperative corneal power.

Several previous studies derived their improved methods according to magnitude of SE Change post-pre by using various topographer models. ${ }^{17-20}$ Hamed et al. derived the regression equation by using the EyeSys with HM as the standard comparison on post myopic LASIK eyes. They proposed for every diopter of operative correction, $0.15 \mathrm{D}$ of effective 
refractive corneal power $\left(\mathrm{EffRP}_{\mathrm{adj}}=\mathrm{EffRP}-0.15[\mathrm{SE}\right.$ Change $_{\text {post-pre }}$-0.05). They found that $70 \%$ of eyes were within $\pm 0.50 \mathrm{D}$ of $\mathrm{HM}$ values ${ }^{17}$ which the accuracy was lower than ours. Besides, Shammas et al. proposed $0.23 \mathrm{D}$ of $\mathrm{K}_{\text {post }}$ obtained from videokeratographer must be adjusted for each diopter of operative correction $\left(\mathrm{K}_{\mathrm{c} . \mathrm{rd}}=\mathrm{K}_{\text {post }}-0.23\right.$ [SE Change $\left.\left.\mathrm{e}_{\text {post-pre }}\right]\right)$. The $\mathrm{K}_{\mathrm{c} . \mathrm{rd}}$ was extremely correlated to the HM value $(r=0.97)^{18}$ which was comparable to those we obtained in this study $(r=0.98)$. Wang et al. found a multiplier of $0.19 \mathrm{D}$ for the Humphrey topographer $\left(\mathrm{K}_{\text {post }}=\right.$ central topographic power -

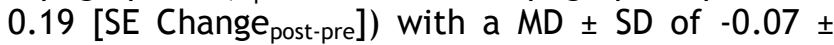
$0.20 \mathrm{D}$ from double-K Holladay 2 back-calculated corneal power ${ }^{19}$ which was consistent to this current finding $(M D \pm S D: 0.00 \pm 0.34)$. Awwad et al. suggested a multiplier of $0.16 \mathrm{D}$ for the $3.0 \mathrm{~mm}$ diameter of average central corneal power $\left(\mathrm{ACCP}_{3 \mathrm{~mm}}\right)$ TMS topographer in each diopter of operative correction $\left(\mathrm{ACCP}_{\mathrm{adj}}=\mathrm{ACCP}_{3 \mathrm{~mm}}-0.16[\mathrm{SE}\right.$ Change $\left._{\text {post-pre }}\right)^{20}$ with $67 \%$ of eyes were within double-K Holladay 1 back-calculated corneal power which was lower than our finding. This discrepancy was contributed to the use of different standard comparison (HM value versus back-calculated corneal power) and different subjects groups (post laser refractive surgery without phacoemulsification versus post LASIK who had undergone phacoemulsification).

This study also found that the direct measurement using the IOLMaster failed to measure the post laser refractive surgery corneal power accurately. This finding was in line with report by Razmju and colleagues ${ }^{21}$ where they had conducted on post PRK eyes only. Similarly, the topographer significantly overestimated the postoperative corneal power as reported in several literatures. ${ }^{17-20}$ Keratometry instruments yielded a misleading measurement because the instruments only measure the paracentral cornea at 2.5 to $3.0 \mathrm{~mm}$ diameter and ignored the ablated region at central corneal.

\section{Limitations}

There are insufficient number of post myopic laser refractive surgery subjects who had subsequently developed cataract to be found in our cohort. Thus, the accuracy of this newly modified equation cannot be extended for further validation. Future study to verify the accuracy of this $C_{2} M_{\bmod }$ on a large number of cases is warranted.

\section{CONCLUSION}

The CLM mod equation produces an accurate postoperative corneal power. Therefore, this equation is recommended as an option when the pre laser refractive surgery keratometry is inaccessible.

\section{ACKNOWLEDGEMENT}

This research is financially supported by the IIUM research funding (IIUM/202/C/1/1/4891).

\section{REFERENCES}

1. Savini G, Hoffer KJ, Carbonelli M, Barboni P. Intraocular lens power calculation after myopic excimer laser surgery: Clinical comparison of published methods. J Cataract Refract Surg 2010; 36:1455-65.

2. Buratto L, Slade $S$, Tavolato $M$. LASIK the evolution of refractive surgery. $2^{\text {nd }}$ ed. USA: SLACK Incorporation, 2012.

3. Tang M, Chen A, Li Y, Huang D. Corneal power measurement with Fourier-domain optical coherence tomography. J Cataract Refract Surg 2010; 36:2115-22.

4. Aramberri J. Intraocular lens power calculation after corneal refractive surgery: Double-K method. J Cataract Refract Surg 2003; 29:20638.

5. Mesa-Gutierrez JC, Rouras-Lopez A, CabiroBadimon I, et al. Intraocular lens power calculation after myopic excimer laser surgery with no previous data. J Emmetropia 2011; 2:97 -102 .

6. Jin H, Auffarth GU, Guo H, Zhao P. Corneal power estimation for intraocular lens power calculation after corneal laser refractive surgery in Chinese eyes. J Cataract Refract Surg 2012; 38:1749-57.

7. Yang R, Yeh A, George MR, et al. Comparison of intraocular lens power calculation methods after myopic laser refractive surgery with previous refractive surgery data. J Cataract Refract Surg 2013; 39:1327-35.

8. Potvin R, Hill W. New algorithm for intraocular lens power calculations after myopic laser in situ keratomileusis based on rotating Scheimpflug camera data. J Cataract Refract Surg 2015; 41:339-47.

9. Haigis W. Intraocular lens calculation after refractive surgery for myopia: Haigis-L formula. J Cataract Refract Surg 2008; 34:1658-63.

10. Arce CG, Soriano ES, Weisenthal RW, Hamilton SM, Rocha KM. Calculation of intraocular lens power using Orbscan II quantitative area topography after corneal refractive surgery. J Refract Surg 2009; 25:1061-74.

11. Joslin C, Koster J, Tu EY. Contact lens overrefraction variability in corneal power 
estimation after refractive surgery. J Cataract Refract Surg 2005; 31:2287-92.

12. Zeh WG, Koch DD. Comparison of contact lens over refraction and standard keratometry for measuring corneal curvature in eyes with lenticular opacity. J Cataract Refract Surg 1999; 25:898-903.

13. Kim JH, Lee DH, Joo CK. Measuring corneal power for intraocular lens power calculation after refractive surgery: comparison of methods. J Cataract Refract Surg 2002; 28:19328.

14. Taheri SMR, Kheiltash A, Hashemi $H$. Comparison of corneal power and intraocular lens power calculation methods after LASIK for myopia. Iranian J Ophthal 2009; 21:45-54.

15. Haigis W. Corneal power after refractive for myopia: contact lens method. J Cataract Refract Surg 2003; 29:1397-411.

16. Qazi MA, Cua IY, Roberts CJ, Pepose JS. Determining corneal power using Orbscan II videokeratography for intraocular lens calculation after excimer laser surgery for myopia. J Cataract Refract Surg 2007; 33:21-30.

17. Hamed AM, Wang L, Misra M, Koch DD. A comparative analysis of five methods of determining corneal refractive power in eyes that have undergone myopic laser in situ keratomileusis. Ophthalmology 2002; 109:651-8.

18. Shammas HJ, Shammas MC, Garabet, A. Correcting the corneal power measurements for intraocular lens power calculations after myopic laser in situ keratomileusis. Am J Ophthalmol 2003; 136:426-32.

19. Wang L, Booth MA, Koch DD. Comparison of intraocular lens power calculation methods in eyes that have undergone laser-assisted in-situ keratomileusis. Trans Am Ophthalmol Soc 2004; 102:189-96.

20. Awwad ST, Manasseh C, Bowman RW. Intraocular lens power calculation after myopic laser in situ keratomileusis: estimating the corneal refractive power. J Cataract Refract Surg 2008; 34:1070-6.

21. Razmju H, Rezaei L, Nasrollahi K, et al. IOLMaster versus manual keratometry after photorefractive keratectomy. J Ophthalmic Vis Res 2011; 6:160-5. 